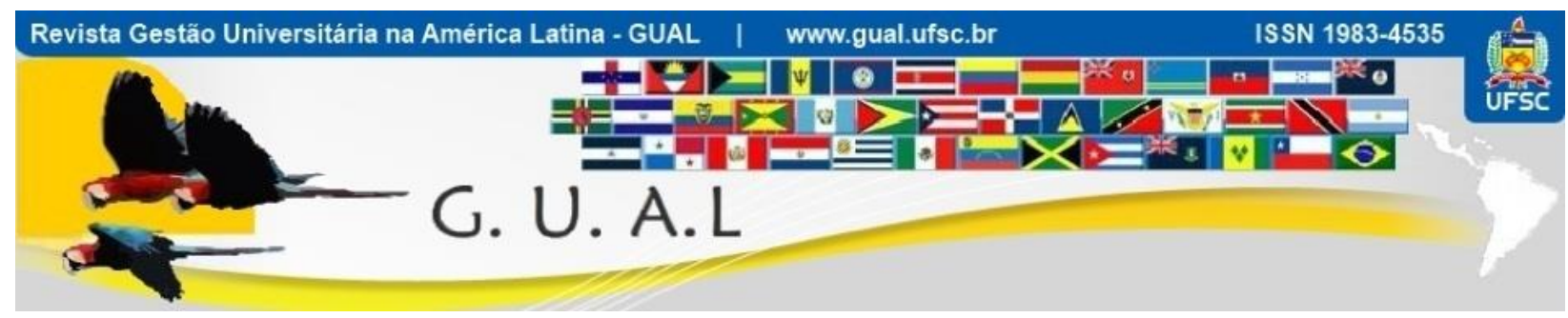

DOI: http://dx.doi.org/10.5007/1983-4535.2014v7n3p182

\title{
AVALIAÇÃO DE DESEMPENHO DE TÉCNICO- ADMINISTRATIVOS EM EDUCAÇÃO NO ÂMBITO DAS INSTITUIÇÕES FEDERAL DE ENSINO SUPERIOR
}

\section{PERFORMANCE EVALUATION OF ADMINISTRATIVE TECHNICAL EDUCATION UNDER THE FEDERAL INSTITUTIONS OF HIGHER EDUCATION}

André de Lima Xandó Baptista, Mestre Universidade Federal de Juiz de Fora - UFJF andrexando@hotmail.com

Marcos Tanure Sanabio, Doutor Universidade Federal de Juiz de Fora - UFJF mtanure.sanabio@ufjf.edu.br

Recebido em 23/junho/2013

Aprovado em 17/abril/2014

Sistema de Avaliação: Double Blind Review

Esta obra está sob uma Licença Creative Commons Atribuição-Uso. 


\section{RESUMO}

As Instituições Federais de Ensino Superior (IFES) foram demandadas pelo Governo Federal a partir da Lei $\mathrm{n}^{\mathrm{o}} 11.091$, de 12 de janeiro de 2005, a criar diretrizes para instituir uma nova sistemática de avaliação de desempenho para seus servidores, estruturando-a como uma das premissas do Plano de Carreiras dos Cargos Técnico-Administrativos em Educação das Universidades Federais. Os objetivos dessa avaliação de desempenho consistiam em promover a melhoria da qualificação dos serviços públicos, subsidiar a política de gestão de pessoas das instituições, principalmente quanto à capacitação, desenvolvimento no cargo e carreira, remuneração e movimentação de pessoas. No entanto, nem todas as IFES se apropriaram dessa ferramenta de maneira adequada e, ao invés de incorporarem o instrumento, associando aos seus sistemas de gestão e aos planos de desenvolvimento institucionais, muitas passaram a utilizá-la de maneira burocrática e corporativista. O presente trabalho pretende investigar os processos de avaliação de desempenho de servidores técnicoadministrativos em educação e analisar os impactos dessa regulamentação nas políticas de Recursos Humanos desenvolvidas pelas universidades. Foram investigados os instrumentos avaliativos e nas regulamentações internas de uma amostra de 18 universidades federais e se os métodos de avaliação utilizados estão correlacionados aos sistemas de gestão e aos Planos de Desenvolvimento Institucionais dessas organizações.

Palavras Chave: Avaliação de Desempenho. Gestão de Recursos Humanos. Instituições Federais de Ensino Superior.

\begin{abstract}
Federal Institutions of Higher Education (IFES) were sued by the Federal Government from the Law No. 11.091, of January 12, 2005, to establish guidelines for instituting a new system of performance evaluation to their servers, structuring it as one of assumptions Career Plan of Technical and Administrative Positions in Education of Federal Universities. The objectives of this performance evaluation was to promote the improvement of the qualification of public services, the policy of subsidizing people management institutions, especially regarding the training, development and career in office, compensation and movement of people. However, not all IFES appropriated this tool properly and, instead of incorporating the instrument, combining their management systems and institutional development plans, many began to use it so bureaucratic and corporatist. This paper aims to investigate the processes for evaluating the performance of technical and administrative staff in education and analyze the impact of such regulation on HR policies developed by universities. We investigated the evaluation instruments and the internal regulations of a sample of 18 federal universities and the valuation methods used are related to management systems and the Institutional Development Plans of these organizations.
\end{abstract}

Keywords: Performance Evaluation. Human Resource Management. Federal Universities. 


\section{INTRODUÇÃO}

O objetivo do presente artigo é investigar como as Instituições Federais de Ensino Superior (IFES) se apropriaram da ferramenta da Avaliação de Desempenho de servidores, instituída como um dos componentes do Plano de Cargos e Carreira dos Técnicos Administrativos em Educação (PCCTAE), preconizado através da Lei 11.091/05.

Até a proposição dessa Lei, as avaliações de desempenho eram dissociadas das carreiras dos servidores públicos, dando retornos pontuais referentes a alguns atributos individuais, desconectado dos objetivos institucionais, servindo em alguns momentos como instrumento punitivo e, muitas vezes, reforçando alguns aspectos corporativistas da máquina estatal. Conforme apontado por Bresser-Pereira (1996) e Campante (2003), as culturas patrimonialistas e burocráticas permearam o serviço público desde a época do império até um passado recente, fazendo o com que a administração pública funcionasse para o benefício de poucos e poderosos em um primeiro momento, e posteriormente de forma mecânica, enrijecida, de alto custo e baixa qualidade.

Um novo modelo de gestão pública surge a partir dos anos 90 supostamente como ideal, através da reforma de modernização do estado promovida no governo Fernando Henrique Cardoso. De acordo com Paes de Paula (2003), é introduzida na Administração Pública a cultura gerencial, importada das políticas neoliberais estadunidenses e inglesas, cujo objetivo original seria de imprimir um código de valores e condutas, orientando a organização das atividades garantindo eficiência e competitividade. Posteriormente segundo a mesma autora, surge a partir de experiências populares dos governos do Partido dos Trabalhadores PT, ganhando força no Governo Lula nos anos 2000, a vertente da Administração Pública Societal onde as participações populares ganham força nos espaços públicos de negociações e deliberativos.

Neste contexto, muitos desafios foram impostos as Universidades Federais Brasileiras na última década, principalmente pelas implementações das avaliações das universidades efetuadas pelo Sistema Nacional de Avaliação do Ensino Superior (SINAES) ${ }^{\mathrm{i}}$ e da forte ampliação e aumento do número de vagas proporcionada pelo Programa de Apoio a Planos de Reestruturação e Expansão das Universidades Federais (REUNI) ${ }^{\text {ii }}$. Essas iniciativas passaram a exigir uma mudança de comportamento por parte dos servidores técnico-administrativos e docentes, no sentido de atender aos requisitos necessários para que os cursos de graduação do ensino superior com avaliações deficitárias não fossem descredenciados e que os cursos já 


\section{AVALIAÇÃO DE DESEMPENHO DE TÉCNICO-ADMINISTRATIVOS EM EDUCAÇÃO NO ÂMBITO DAS INSTITUICCÕES FEDERAL DE ENSINO SUPERIOR \\ DOI: http://dx.doi.org/10.5007/1983-4535.2014v7n3p182}

consolidados passassem a obter melhores posições nas avaliações, num cenário onde a ampliação do atendimento do número de alunos passa a exigir uma maior qualidade dos serviços prestados a comunidade universitária a cada dia.

No momento em que as Universidades Federais passam a atender os requisitos estabelecidos pelas dimensões avaliadas pelo SINAES, uma das obrigações firmadas entre as instituições e o Ministério da Educação (MEC), foi a apresentação do Plano de Desenvolvimento Institucional (PDI), com o planejamento das ações de ensino, pesquisa e extensão a serem executadas no período de 2009 a 2013.

Neste ínterim, o Governo Federal publica em 2008 a Medida Provisória 431, posteriormente convertida na Lei 11.784 , que alinha os procedimentos de avaliação de desempenho de servidores Técnicos-Administrativos em Educação (TAE’s) ao cumprimento de metas individuais e institucionais das organizações da Administração Pública Federal.

A avaliação de desempenho é um dispositivo que pode apresentar eficiência e eficácia, desde que adequadamente adaptado às particularidades e cultura das pessoas e da Instituição. Diante dessa conjuntura, utilizar a ferramenta da avaliação de desempenho como um instrumento de gestão, que proporcione aos dirigentes das unidades acadêmicas e administrativas efetuarem ações coordenadas, no sentido de convergir um eventual sistema de metas individuais e de equipes de trabalho para o atendimento das necessidades institucionais, exigidas pelos programas de expansão e avaliação da educação superior, pode se tornar um diferencial competitivo para o alcance dos resultados desejados.

A metodologia utilizada no trabalho é de pesquisa qualitativa e estudo de caso de uma amostra de 18 IFES, a partir de análise documental secundária das resoluções que regulamentam em cada uma dessas instituições a implantação de programa de avaliação de desempenho dos TAE's e os seus instrumentos. As informações obtidas foram correlacionadas com os métodos avaliativos e os sistemas de gestão de RH investigados, visando identificar componentes comuns e melhores práticas nas organizações.

Este trabalho foi disposto estruturalmente em cinco seções composto inicialmente pela Introdução, que contextualiza a questão da Avaliação de Desempenho nas Universidades Federais de Ensino Superior. Na $2^{\mathrm{a}}$ seção promove-se uma discussão teórica sobre a Avaliação de Desempenho no Setor Público: histórico e legislação; das competências e métodos de avaliação de desempenho e dos dois modelos de Recursos Humanos utilizados na pesquisa (ULRISH, 1998 e TANURE, EVANS e PUCIK, 2007). 


\section{AVALIAÇÃO DE DESEMPENHO DE TÉCNICO-ADMINISTRATIVOS EM EDUCAÇÃO NO ÂMBITO DAS INSTITUIÇÕES FEDERAL DE ENSINO SUPERIOR \\ DOI: http://dx.doi.org/10.5007/1983-4535.2014v7n3p182}

A seção 3 apresenta a metodologia do trabalho, caracterizada por uma pesquisa qualitativa e estudo de caso de 18 IFES. Na $4^{\text {a }}$ seção são analisados os resultados do trabalho, em especial na identificação dos métodos de avaliação de desempenho e das funções efetivas do setor de recursos humanos nas instituições pesquisadas. Finaliza-se o trabalho na seção 5 com as conclusões, além das referências.

\section{FUNDAMENTAÇÃO TEÓRICA}

\subsection{AVALIAÇÃO DE DESEMPENHO NO SETOR PÚBLICO: HISTÓRICO E LEGISLAÇÃO}

Para compreender como melhorar as práticas profissionais dos servidores públicos diante do desejado contexto, democrático, participativo, transparente, onde as exigências da população são cada vez mais veementes, será investigado, historicamente, como foram estruturadas as políticas de avaliação de desempenho, desde as mais rudimentares até as mais recentes, participativas e inclusivas, traduzindo em ações de melhoria e qualidade no setor público, que ao longo do tempo, sempre esteve associada aos sistemas produtivos, conforme explicitado por Lucena (2004):

A prática da avaliação, entendida no seu sentido genérico, é tão antiga quanto o próprio homem. É o exercício da análise e do julgamento sobre a natureza, sobre o mundo que nos cerca e sobre as ações humanas. É a base para apreciação de um fato, de uma ideia, de um objetivo ou de um resultado e, também, a base para tomada de decisão sobre qualquer situação que envolva uma escolha. Se esta afirmação é verdadeira, todo ato humano é o resultado de um processo de avaliação, que gera consequentemente no desdobramento feito ou da decisão tomada. Os acertos e os desacertos, as conquistas e as perdas, o progresso e o imobilismo, a paz e a guerra, a riqueza e a pobreza, a criatividade e a imitação, enfim, todos os contrastes da vida humana são consequências de julgamentos firmados e de decisões assumidas, originário do processo avaliativo (LUCENA, 2004).

A avaliação de desempenho como uma ferramenta de gestão nas organizações não é uma prática recente, afirma Chiavaneto (1998). Os primeiros registros ocorreram no início do século IV, a Companhia de Jesus utilizava de um sistema combinado de relatórios e notas de atividade, consistindo em um sistema de autoclassificação. Há registros do Serviço Público Federal dos EUA em 1842, quando se implantou um sistema de relatórios anuais para avaliar o desempenho dos funcionários. Também em 1880, no exército americano, e em 1918 na 


\section{AVALIAÇÃO DE DESEMPENHO DE TÉCNICO-ADMINISTRATIVOS EM EDUCAÇÃO NO ÂMBITO DAS INSTITUIÇÕES FEDERAL DE ENSINO SUPERIOR \\ DOI: http://dx.doi.org/10.5007/1983-4535.2014v7n3p182}

General Motors instituíram sistemas de avaliação. No entanto, Gil (2001), aponta que na formação da Escola da Administração Científica, dada no fim do século XIX, início do século XX, seus representantes maiores, Taylor, Ford e Fayol, já orientavam processos avaliativos visando reduzir os tempos e custos de produção na indústria e aumentar a produtividade dos trabalhadores.

No Brasil, segundo Santos e Cardoso (2001), a avaliação de desempenho surge nos anos 70, vinculada ao sistema remuneratório e ao desenvolvimento de carreiras do setor público, a partir da Lei $\mathrm{n}^{\circ} 5.645 / 70$ e do Decreto $\mathrm{n}^{\circ} 80.602 / 77$, sem ter conseguido obter grande sucesso naquele momento.

Velasco e Silva (2010) explicam que com a edição do Decreto $n^{\circ} 84.699 / 80$, revoga-se o Decreto $\mathrm{n}^{\circ} 80.602$, modificando os conceitos regulados anteriormente, passando a definir a progressão, como vertical, essa somente se houvesse vaga para ser concedida, e o "aumento por mérito" como progressão horizontal.

O Regime Jurídico Único dos servidores públicos e civis da União, Lei nº 8.112/1990, que dispõe sobre os servidores públicos civis da União, das autarquias e das fundações públicas federais, prevê em seu art. 20 a avaliação do desempenho para aprovação no estágio probatório, observados os seguintes fatores: assiduidade, disciplina, capacidade de iniciativa, produtividade e responsabilidade. Em 1994, implementou-se na esfera federal, regulamentos de avaliação de desempenho individual vinculados ao pagamento das diversas gratificações de desempenho já existentes. Já a Emenda Constitucional nº 19/98, introduziu em seus artigos algumas situações para as quais estavam previstas a avaliação de desempenho.

Para Velasco e Silva (2010), as gratificações de desempenho anteriores a 1995, embora tenham sido criadas com o objetivo de avaliarem o desempenho, foram se desvirtuando ao longo do tempo, até passarem a ser pagas a todos os servidores com valores fixos em razão de dificuldades de implementação de mecanismos eficazes de avaliação.

Pela Medida Provisória $n^{\circ}$ 1.548/96 foi aprovada a Gratificação de Desempenho e Produtividade (GDP), convertida na Lei $n^{\circ}$ 9.625/98 recuperando o conceito da Avaliação do Desempenho como base na remuneração, consolidando um modelo e um referencial que passou a ser seguido por muitas carreiras que adotaram gratificações do mesmo tipo e correspondeu a uma "cesta de pontos", em que cada ponto corresponde a um percentual do vencimento-base. 


\section{AVALIAÇÃO DE DESEMPENHO DE TÉCNICO-ADMINISTRATIVOS EM EDUCAÇÃO NO ÂMBITO DAS INSTITUICCÕES FEDERAL DE ENSINO SUPERIOR \\ DOI: http://dx.doi.org/10.5007/1983-4535.2014v7n3p182}

A Gratificação de Desempenho para as carreiras de Auditoria surgem em junho de 1999, contemplando uma parte relativa à avaliação do desempenho individual e outra relativa à avaliação de desempenho institucional, tendo sido considerado na época um modelo inovador quanto à sua concepção. A partir desse momento começaram a surgir várias gratificações com características semelhantes.

Instituída em fevereiro de 2002, surge a Gratificação de Desempenho de Atividade Técnico-Administrativa (GDATA), destinada aos servidores da área administrativa da Administração Pública Federal direta, autarquias e fundações públicas, abrangendo aproximadamente 300.000 servidores, tendo sua aplicação associada ao desempenho. Juntamente com a GDATA, seguiram-se outras gratificações variáveis em função do desempenho individual, coletivo e/ou institucional, denominadas Gratificações de Desempenho.

De acordo com Balassiano e Salles (2009), as estruturas burocratizadas e a ideologia da isonomia provocaram atraso na implementação de inovação nos sistemas avaliativos da administração pública. Outro fator dificultador apontado naquele momento, a legislação, era a justificativa dos gestores para o imobilismo verificado na maioria das instituições, no que se refere à gestão do desempenho e à obtenção de resultados efetivos.

Atualmente nas organizações públicas, a gestão de pessoas tem passado por profundas transformações, visto a grande necessidade de se oferecer aos cidadãos, serviços públicos com a qualidade e eficiência desejados, almejados e cobrados pela população.

Questionamentos efetuados pela sociedade com relação à qualidade dos serviços prestados pelos servidores públicos, e pelos próprios governos em suas esferas municipal, estadual e federal, motivaram as principais reformas relacionadas à gestão de recursos humanos no serviço público, levando invariavelmente, a transformações dos serviços prestados e da forma de trabalhar dos servidores estatais.

Diante desse novo cenário, a avaliação de desempenho passa a ser definida pelo governo federal como o monitoramento sistemático e contínuo da atuação do servidor civil, enquanto individuo integrante de uma equipe de trabalho e de uma instituição, possuindo como referência a serem alcançadas, metas globais e intermediárias dos órgãos e entidades que compõem o conjunto de carreiras e cargos do Sistema de Pessoal Civil do serviço executivo federal. 


\section{AVALIAÇÃO DE DESEMPENHO DE TÉCNICO-ADMINISTRATIVOS EM EDUCAÇÃO NO ÂMBITO DAS INSTITUICCÕES FEDERAL DE ENSINO SUPERIOR \\ DOI: http://dx.doi.org/10.5007/1983-4535.2014v7n3p182}

Com implantação da Lei 11.091/2005, que dispõe sobre a estruturação do Plano de Carreira dos Cargos Técnico-Administrativos em Educação (PCCTAE), no âmbito das Instituições Federais de Ensino vinculadas ao Ministério da Educação, as universidades federais foram demandadas a atender aspectos referentes à avaliação de desempenho:

Com essas medidas, o Governo Federal dá início à filosofia de gestão pela competência atrelada à carreira do servidor público das IFES, associando às carreiras a avaliação de desempenho baseada no plano estratégico institucional, capacitando e qualificando os servidores para atenderem às demandas organizacionais. A regulação acabou por obrigar as instituições a se adequarem para atender às exigências governamentais, que por consequência afetou diretamente a categoria dos Técnico-Administrativos em Educação, fazendo com que a legislação proporcionasse melhorias forçadas nas equipes de trabalho. Observa-se que apesar de regulamentar, o governo dá liberdade para cada instituição desenvolver seu próprio modelo e sistemática avaliativa.

O Decreto 5.707/2006 propõe a instituição da Política e as Diretrizes para o Desenvolvimento de Pessoal da administração pública federal direta, autárquica e fundacional, regulamentando dispositivos da Lei 8.112/90. Foi proposta no sentido de complementar a Lei 11.091/05 no estabelecimento de diretrizes para os planos de capacitação das instituições, agregadas à avaliação de desempenho, procurando em suas lacunas, habilidades e competências necessárias para que os servidores se integrem com mais qualidade às suas equipes de trabalho.

A partir da Medida Provisória 431, editada em 2008, convertida posteriormente na Lei $\mathrm{n}^{\circ} 11.784 / 2008$, é instituída a sistemática de avaliação de desempenho para as demais carreiras da Administração Pública Federal direta, autárquica e fundacional. Diferentemente dos servidores das IFES, onde a avaliação é obtida como um pré-requisito para a progressão por mérito, as demais carreiras atendidas por essa legislação fica instituída uma gratificação complementar agregada à avaliação de desempenho, só fazendo jus a recebê-la o servidor que conseguir atingir as metas de desempenho individual e institucional. Estabelece estímulos para que os servidores se qualifiquem em cursos de pós-graduação stricto sensu, validando-os como cargas horárias para progressão por capacitação na carreira do PCCTAE.

A publicação do Decreto $\mathrm{n}^{\circ} 7.133 / 2010$ definiu regulamentação dos critérios e procedimentos gerais a serem observados para a realização das avaliações de desempenho individual e institucional. Este Decreto detalha um pouco mais os dispositivos da Lei ${ }^{\circ}$ 
11.784/2008, consolidando em um único ato normativo, diretrizes gerais a serem seguidas pelos órgãos e entidades para a realização de processos avaliativos individuais dos seus servidores e a avaliação institucional do órgão ou entidade, visando o pagamento de gratificações de desempenho de 47 categorias funcionais da administração direta, indireta e autárquica da união.

Para Velasco e Silva (2010), a inovação instituída com essas últimas e novas regulamentações visava à padronização dos procedimentos orientadores da sistemática de avaliação de desempenho do setor público, trazendo um viés construtivista, fomentando a participação em equipe e fazendo com que a democratização das relações de trabalho passasse a constituir o eixo principal dessa política, as autoras afirmam:

Essas práticas democráticas das relações de trabalho no serviço público pressupõem a possibilidade de o servidor organizar-se e fazer-se representar por seus pares, mote preliminar da democracia. Dessa forma, as principais ferramentas de gestão participativa contida na sistemática são: a avaliação $360^{\circ}$, a instituição da Comissão de Acompanhamento da Avaliação de Desempenho - CAD e do Comitê Gestor da Avaliação de Desempenho (VELASCO e SILVA, 2010, p. 7).

\subsection{AVALIAÇÃO DE DESEMPENHO; COMPETÊNCIAS E MÉTODOS}

A avaliação de desempenho humano, de acordo com Chiavenato (1998), pode ser realizada através de diversas técnicas, que podem variar intensamente conforme a cultura das organizações. Até mesmo dentro de uma única organização, ela pode acontecer de maneiras diferentes, de acordo com o nível do trabalhador na hierarquia da empresa e até mesmo da área na qual ele trabalha. Geralmente as sistemáticas de avaliação de desempenho humano atendem a determinados objetivos, traçados com base em determinada política de RH. Essas avaliações devem ser efetuadas com relação às competências funcionais, individuais e das equipes de trabalho, dentro de suas especificidades.

A comparação entre essas competências necessárias ou resultados esperados e as competências já disponíveis ou resultados alcançados permite, então, identificar as lacunas ou discrepâncias existentes. Tal avaliação segundo Brandão (2009) permitirá a correção dos desvios, bem como o reconhecimento, a premiação e a remuneração das pessoas e das equipes com base no desempenho demonstrado.

O conceito de verificação e apuração das competências e atribuições de trabalhadores surge, segundo Mesquita (2010), quando McClelland (1973) lança o livro "Testing for Competencies rather intelligence". Nessa publicação fica nítida a insatisfação do autor ante os 


\section{AVALIAÇÃO DE DESEMPENHO DE TÉCNICO-ADMINISTRATIVOS EM EDUCAÇÃO NO ÂMBITO DAS INSTITUICCÕES FEDERAL DE ENSINO SUPERIOR \\ DOI: http://dx.doi.org/10.5007/1983-4535.2014v7n3p182}

métodos tradicionais de seleção utilizados pela psicologia, para prever o rendimento futuro no trabalho. Passam-se então à busca de outras variáveis, as chamadas "competências", permitindo uma nova compreensão do rendimento no trabalho.

Nessas pesquisas, McClelland objetivava descobrir variáveis que tentassem prever com exatidão o rendimento eficaz no posto de trabalho. Para o autor, os tradicionais exames acadêmicos de atitude e conhecimento, e as qualificações e títulos não previam o rendimento que se teria no trabalho, nem o êxito na vida. As competências poderiam ser previsoras do rendimento no trabalho.

Formularam-se dois princípios fundamentais para a investigação: utilização de amostras de critérios para comparar pessoas que tiveram êxito tanto profissional como pessoal com pessoas de menor êxito nestes dois campos de vida, visando identificar características e comportamentos que proporcionassem alguma relação de causa e efeito com esse êxito. Era necessário estudar as pessoas diretamente no trabalho, comparando as características dos de melhor desempenho com as dos trabalhadores de rendimento médio e baixo.

São muitas as definições de competência, em sua maioria complementares, entre elas, a definição de Trujillo (1999) que a entende como uma característica subjacente de um indivíduo, causalmente relacionada com um rendimento efetivo ou superior em uma situação ou trabalho, definido em termos de um critério. Para Zarifian (2008) "competência é o "tomar iniciativa" e "o assumir responsabilidade" do indivíduo diante de situações profissionais com as quais se depara”. Le Boterf (2003) diz que, competência é um saber agir responsável, como tal reconhecido pelos outros, saber como mobilizar, integrar recursos e transferir os conhecimentos, recursos e habilidades, em situações profissionais determinadas. Já para Fleury e Fleury (2004:27) competência é uma característica subjacente a uma pessoa, relacionada com desempenho superior na realização de uma tarefa ou em determinada situação. Para Mesquita (2010), ficam dessa forma, diferenciados pelos diversos autores os seguintes conceitos: competência de aptidões (talento natural da pessoa, que pode vir a ser aprimorado), de habilidades (demonstração de um talento particular na prática) e de conhecimentos, (o que a pessoa precisa saber para desempenhar uma tarefa).

A identificação das competências é parte vital da estratégia empresarial, inicia-se pela definição das competências organizacionais e desdobra-se em competências funcionais, podendo também acontecer da forma inversa. A análise das competências de cada profissional 


\section{AVALIAÇÃO DE DESEMPENHO DE TÉCNICO-ADMINISTRATIVOS EM EDUCAÇÃO NO ÂMBITO DAS INSTITUICCÕES FEDERAL DE ENSINO SUPERIOR \\ DOI: http://dx.doi.org/10.5007/1983-4535.2014v7n3p182}

formaria o portfólio de competências organizacionais, definindo-se então a estratégia no mercado.

Ainda, Mesquita (2010) afirma que os estudiosos franceses exerceram forte influência sobre o pensamento brasileiro no conceito de competências - autores como Le Boterf e Philippe Zarifian contrapuseram-se à visão americana de David McClelland, Spencer e Spencer e Paul Green. Para o autor, a visão francesa enfatiza o social e a visão americana o comportamento e os resultados. A conjunção dessas duas correntes forma a base para a visão dos autores brasileiros.

Assim como o entendimento de competência varia de acordo com cada organização, as políticas de RH seguem essa diversidade. Não há de estranhar que cada universidade desenvolva a sua própria sistemática de medição da conduta profissional de seus funcionários. De maneira geral, a aplicação do pessoal é definida conforme as posições dos cargos, o nível hierárquico ocupado, normalmente são utilizados mais de um tipo de avaliação de desempenho. Cada sistemática atende a determinados objetivos específicos e características das várias categorias de pessoal. Há vertentes que supõem que a avaliação de desempenho não deixa de ser uma boa sistemática de comunicação, atuando no sentido horizontal e vertical da organização.

Nesse sentido, torna-se central a investigação dos diversos métodos de avaliação de desempenho existentes, para posteriormente identificar quais métodos são utilizados pelas Instituições Federais de Ensino Superior, e como essas se apropriaram desses métodos avaliativos para aplicar em seus servidores na busca do atendimento às legislações e aos melhores resultados institucionais.

De acordo com Chiavenato (1998), a avaliação dos indivíduos que desempenham um papel dentro da organização pode ser feita por meio de várias abordagens, e recebem diversas denominações: avaliação do desempenho, avaliação do mérito, avaliação dos empregados, relatório de progresso e avaliação de eficiência funcional. Pode-se resumir a avaliação de desempenho como um conceito dinâmico, visto que os empregados são sempre avaliados, sejam formal ou informalmente, havendo, normalmente, certa continuidade dentro das organizações. É um instrumento pelo qual a organização pode localizar problemas de supervisão de pessoal, de integração com o empregado a organização ou ao cargo que ocupa, de discordâncias, de desaproveitamento de empregados de potencial mais elevado do exigido pelo cargo, de motivação, entre outros. 


\section{AVALIAÇÃO DE DESEMPENHO DE TÉCNICO-ADMINISTRATIVOS EM EDUCAÇÃO NO ÂMBITO DAS INSTITUIÇÕES FEDERAL DE ENSINO SUPERIOR \\ DOI: http://dx.doi.org/10.5007/1983-4535.2014v7n3p182}

Diversos métodos e conceitos são relacionados ao desempenho, o mesmo se estende às metodologias de mensuração. Os métodos mais tradicionais de avaliação, segundo Pontes (1987), são criticados, pois se baseavam na análise e classificação do comportamento apresentado pelo indivíduo no passado, sem nenhum vínculo ao compromisso futuro junto às organizações, são rotineiros, repetitivos e burocráticos. Pode-se, então, enumerar a seguir, alguns métodos tradicionais utilizados para essa finalidade: Método da Escala Gráfica, Método da Escolha Forçada, Método da Pesquisa de Campo, Método dos Incidentes críticos, Método da comparação de pares, Método da auto-avaliação, Método do relatório de performance, Método de Padrões de Desempenho. Ainda, se podem listar outros métodos de avaliação denominados de contemporâneos, como: Método da Avaliação de Resultados ou por Objetivos, Avaliação de desempenho por múltiplas fontes, Avaliação $360^{\circ}$, Avaliação por Balance Scorecard.

\subsection{OS MODELOS DE RECURSOS HUMANOS}

O atrelamento dos sistemas de avaliação disponíveis na Teoria das Organizações somente será efetivo e eficaz quando correlacionado com os objetivos da instituição. Caso contrário, estar-se somente avaliando por avaliar, desvinculado da realidade presente e futura das organizações.

Nesse sentido, apresenta-se os modelos de Ulrish e das Quatro Faces dos Recursos Humanos, que utilizam metodologias que visam integrar as políticas de gestão de pessoas com as práticas profissionais em todos os níveis das organizações, do operacional ao estratégico.

\subsubsection{O Modelo de Ulrich}

O modelo de Ulrish (1998) delineia os quatro papéis principais que a gestão de pessoas de uma organização deve ter: Administração de Estratégias de Recursos Humanos, Administração da Infraestrutura da Empresa, Administração da Contribuição dos Funcionários e a Administração da Transformação e da Mudança, conforme podemos observar na Figura 1. 


\section{AVALIAÇÃO DE DESEMPENHO DE TÉCNICO-ADMINISTRATIVOS EM EDUCAÇÃO NO ÂMBITO DAS INSTITUIÇÕES FEDERAL DE ENSINO SUPERIOR \\ DOI: http://dx.doi.org/10.5007/1983-4535.2014v7n3p182}

\begin{tabular}{|c|c|c|c|}
\hline \multicolumn{4}{|c|}{ Foco no Futuro/Estratégico } \\
\hline \multirow{6}{*}{ Processos } & Administracão de Fstratégias & Administração da & \multirow{5}{*}{ Pessoal } \\
\hline & de Recursos Humanos & Transformação e da & \\
\hline & & $\begin{array}{l}\text { Muduança } \\
\text { duminatron }\end{array}$ & \\
\hline & Administração da & Admınıstraçao da & \\
\hline & Infraestrutura da Empresa & $\begin{array}{l}\text { Funcionários } \\
\text { Futros }\end{array}$ & \\
\hline & \multicolumn{3}{|c|}{ Foco no Cotidiano/Operacional } \\
\hline
\end{tabular}

Figura 1 Modelo dos quatro papéis da gestão de pessoas Fonte: (ULRICH, 1998, p. 40)

De acordo com Ulrich (1998), os dois eixos representam o foco e as atividades dos profissionais da área de gestão de pessoas, indo o foco do estratégico de longo prazo ao operacional de curto prazo. Os gestores das organizações devem aprender ser ao mesmo tempo estratégicos e operacionais, focando-se tanto no longo prazo quanto no curto prazo.

As atividades desses profissionais segundo o autor, devem se estender da administração de processos à administração de pessoas. Esses dois eixos delineiam os quatro principais papéis dos gestores apresentados por esse modelo. Para melhor compreender, detalha-se no Quadro 1 o papel/função, resultados, metáfora e atividades.

\begin{tabular}{|l|l|l|l|}
\hline Papel/Função & Resultado & Metáfora & Atividade \\
\hline $\begin{array}{l}\text { Administração de } \\
\text { Estratégias de Recursos }\end{array}$ & Execução da Estratégia & Parceiro Estratégico & $\begin{array}{l}\text { Ajuste das estratégias de RH à } \\
\text { estratégia empresarial: } \\
\text { 'Diagnóstico organizacional' }\end{array}$ \\
\hline $\begin{array}{l}\text { Administração da Infra- } \\
\text { estrutura da empresa }\end{array}$ & $\begin{array}{l}\text { Construção de uma } \\
\text { infra -estrutura eficiente }\end{array}$ & $\begin{array}{l}\text { Especialista } \\
\text { Administrativo }\end{array}$ & $\begin{array}{l}\text { Reengenharia dos Processos de } \\
\text { Organização: 'Serviços em } \\
\text { Comum' }\end{array}$ \\
\hline $\begin{array}{l}\text { Administração da } \\
\text { Contribuição dos }\end{array}$ & $\begin{array}{l}\text { Aumento do } \\
\text { envolvimento e } \\
\text { Fupacidade dos } \\
\text { funcionários }\end{array}$ & $\begin{array}{l}\text { Defensor dos } \\
\text { Funcionários }\end{array}$ & $\begin{array}{l}\text { Ouvir e responder aos } \\
\text { funcionários: 'Prover recursos aos } \\
\text { funcionários' }\end{array}$ \\
\hline $\begin{array}{l}\text { Administração da } \\
\text { Transformação e da } \\
\text { Mudança }\end{array}$ & $\begin{array}{l}\text { Criaño de uma } \\
\text { organazão renovada }\end{array}$ & Agente da Mudança & $\begin{array}{l}\text { Gerir a transformação e a } \\
\text { mudança: 'Assegurar capacidade } \\
\text { para mu dança' }\end{array}$ \\
\hline
\end{tabular}

Quadro 1 Definição dos papéis da gestão de pessoas

Fonte: (ULRICH, 1998, p. 41).

Dessa forma, de acordo com Hanashiro et al (2003) o papel dos profissionais da área de gestão de pessoas passa pela elaboração de políticas e práticas agregadoras de valores aos seus stakeholders ${ }^{i i i}$ e na orientação e qualificação dos gestores, para assumirem o papel complementar de gestor de pessoas. O foco das políticas de gestão de pessoas deixa de ter uma perspectiva somente interna e passa a ter a visão de agregação de valores necessários para as melhorias e mudanças institucionais. Ulrich (1998) defende uma mudança de mentalidade dos colaboradores, passando da ênfase "o que eu faço" para a ênfase "o que eu entrego", abolindo a visão reducionista e adotando a dimensão sistêmica, múltipla, focada nas necessidades diferenciadas dos stakeholders. 


\section{AVALIAÇÃO DE DESEMPENHO DE TÉCNICO-ADMINISTRATIVOS EM EDUCAÇÃO NO ÂMBITO DAS INSTITUICCÕES FEDERAL DE ENSINO SUPERIOR \\ DOI: http://dx.doi.org/10.5007/1983-4535.2014v7n3p182}

As avaliações de desempenho aplicadas aos TAE's das universidades tem que estar alinhadas às praticas necessárias para realização dos objetivos das IFES, no ajuste integrado, o foco concentra-se na fusão entre o Plano de Desenvolvimentos Institucionais e os de Gestão de Pessoas, onde os gestores e servidores passam a trabalhar como parceiros para garantir a coerência entre os planos em todas as suas dimensões.

\subsubsection{O Modelo das Quatro Faces da Gestão de Recursos Humanos}

O modelo de Ulrich possibilita agregar valor aos procedimentos avaliativos, pactuar objetivos que efetivamente tragam benefícios, almejar a melhoria dos processos estratégicos e operacionais de uma organização.

Contrapondo ao modelo de Ulrich (1998), o Modelo das Quatro Faces da Gestão de Recursos Humanos, proposto pelos pesquisadores Tanure, Evans e Pucik (2007) para identificar se as empresas que atuam no ambiente brasileiro, incluem a área de Recursos Humanos como uma parceira estratégica, na articulação das mudanças organizacionais e quais os fatores críticos que influenciam a configuração desse papel.

Evans, Pucik e Barsoux (2002) propuseram um modelo no qual os gestores devem atuar como construtor, parceiro de mudança e navegador. Esses autores transpõem esse modelo para a realidade brasileira baseados nos resultados de pesquisas e experiências de três décadas em empresas multinacionais e brasileiras, demonstraram a existência de mais uma face ou etapa anterior à de construtor - a de executor.

Segundo os mesmos autores, o desenvolvimento de processos de gestão em Recursos Humanos iniciou no Brasil com quase 50 anos de atraso com relação aos países de primeiro mundo, induzidos pela indústria automobilística nos anos 60, importando praticas gerenciais americanas em um primeiro momento, japonesas a partir dos anos 80 e 90, quando buscaram desenvolver técnicas e práticas de gestão mais modernas, sendo na maioria das vezes benchmark de práticas internacionais.

A partir desses preceitos, os autores defendem a abordagem da divergente convergente $^{\text {iv }}$, admitindo que o conceito universalista seja válido para alguns aspectos da vida organizacional e o relativista para outros, tendo em vista diferenças no contexto legal e cultural em que a empresa se insere.

Diante de mudanças oriundas do cenário cada vez mais competitivo e globalizado, novos papéis passaram a ser exigidos aos profissionais da área de Recursos Humanos e dos 


\section{AVALIAÇÃO DE DESEMPENHO DE TÉCNICO-ADMINISTRATIVOS EM EDUCAÇÃO NO ÂMBITO DAS INSTITUIÇÕES FEDERAL DE ENSINO SUPERIOR \\ DOI: http://dx.doi.org/10.5007/1983-4535.2014v7n3p182}

gestores das instituições. Tanure et al (2007) apresentam quatro faces (ou etapas) essenciais a serem exercidas pela área, caracterizadas como: executor, construtor, parceiro de mudança, navegador. O modelo quatro faces da gestão dos Recursos Humanos é demonstrado no Quadro 2.

\begin{tabular}{|c|c|c|c|c|}
\hline & Atividade & $\begin{array}{l}\text { Foco de } \\
\text { Atenção }\end{array}$ & $\begin{array}{l}\text { Perspectiva } \\
\text { Teórica }\end{array}$ & Função \\
\hline Execução & $\begin{array}{l}\text { Atividades desconectadas da } \\
\text { estratégia, mesmo usando-se } \\
\text { ferramentas sofisticadas }\end{array}$ & Ação & Fazer & EXECUTOR \\
\hline Construção & $\begin{array}{l}\text { Fundamentos - acertando os } \\
\text { elementos básicos }\end{array}$ & $\begin{array}{l}\text { Consistência } \\
\text { interna }\end{array}$ & $\begin{array}{l}\text { Ajuste interno } \\
\text { Adequação }\end{array}$ & CONSTRUTOR \\
\hline Direção & $\begin{array}{l}\text { Capacidade de gerenciar } \\
\text { contextos paradoxais }\end{array}$ & $\begin{array}{l}\text { Tensão construtiva } \\
\text { entre opostos }\end{array}$ & $\begin{array}{l}\text { Dualidade/ } \\
\text { paradoxo }\end{array}$ & NAVEGADOR \\
\hline
\end{tabular}

Quadro 2: As quatro faces de RH

Fonte: Adaptado de Tanure et al , 2007.

\section{MÉTODO DE PESQUISA}

Utiliza-se como metodologia a modalidade de pesquisa qualitativa, considerando que a interpretação dos fenômenos e seus relativos significados são indissociáveis entre o mundo objetivo e a subjetividade, conforme mencionado por Matias-Pereira (2007). Ainda, reforça o presente autor, “o ambiente natural é a fonte direta para coleta de dados e o pesquisador é o instrumento-chave" (MATIAS-PEREIRA, 2007, p.71).

Trata-se de um Estudo de Caso por possibilitar, nas palavras de Motta-Roth e Hendges (2010), "um estudo intensivo de um grupo - organização, instituição com vistas a obter generalizações a partir de uma análise abrangente do tópico de pesquisa" (MOTTA-ROTH E HENDGES, 2010, p. 115). Tal explicação teórica é ratificada por Yin (2001) ao explicitar a metodologia de Estudo de Caso, quando demonstra que para o tipo de questão de pesquisa da forma “como?" e "por quê?" ou quando o foco temporal está em fenômenos contemporâneos dentro do contexto de vida real, é plenamente viável.

Compõem o presente trabalho de pesquisa bibliográfica e de análise documental. Essas metodologias tem o objetivo de identificar, em documentos secundários, informações que sirvam de subsídio para responder a questão investigada. Como representam uma fonte natural de informação, documentos "não são apenas uma fonte de informação contextualizada, mas surgem num determinado contexto e fornecem informações sobre esse mesmo contexto" (LÜDKE e ANDRÉ, 1986, p. 39). Neste caso, a análise documental foi 
utilizada pois a linguagem presente nos documentos constitui-se elemento fundamental para a investigação.

Visando atender ao propósito deste estudo e contribuir para a compreensão dos elementos que influenciam o exercício dos papéis emergentes da área de Recursos Humanos, foi efetuada uma análise documental investigativa de uma amostra de 18 IFES, verificando as resoluções, regulamentos, regimentos, propostas, normas, decisões e manuais que regulamentam em cada instituição a implantação dos programas de avaliação de desempenho dos TAE's e suas respectivas ferramentas avaliativas. As informações obtidas foram correlacionadas aos métodos avaliativos e os sistemas de gestão de RH explicitados no referencial teórico, visando identificar componentes comuns e melhores práticas da regulamentação e ferramental em cada organização

No nosso caso, especificamente, para efetuar a pesquisa desejada, procurou-se extrair uma amostra aleatória de IFES nas 5 regiões geográficas brasileiras, sendo:

Região Norte: Universidade Federal do Pará, UFPA

Região Nordeste: Universidade Federal da Bahia, UFBA, Universidade Federal do Ceará, UFC, Universidade Federal do Pernambuco, UFPE e Universidade Federal do Rio Grande do Norte, UFRN

Região Centro-Oeste: Universidade de Brasília, UnB

Região Sudeste: Universidade Federal de Juiz de Fora, UFJF; Universidade Federal de Minas Gerais, UFMG; Universidade Federal de São Carlos, UFSCar; Universidade Federal de São Paulo, UNIFESP; Universidade Federal de Viçosa, UFV; Universidade Federal do Espírito Santo, UFES; Universidade Federal do Rio de Janeiro, UFRJ; Universidade Federal do Vale do Jequitinhonha e Mucuri, UFVJM e Universidade Federal Fluminense, UFF

Região Sul: Universidade Federal de Santa Catarina, UFSC; Universidade Federal do Paraná, UFPR e Universidade Federal do Rio Grande do Sul, UFRGS.

\section{ANÁLISE DOS RESULTADOS}

A presente seção tem por objetivo apresentar a análise comparativa dos programas de avaliação de desempenho de servidores TAE's das IFES. As informações foram obtidas dos sítios eletrônicos na internet das universidades investigadas, nos setores de avaliação de desempenho relacionados às áreas de Recursos Humanos e/ou Gestão de Pessoas dessas instituições.

De forma concreta, sistematiza-se as informações de identificação das Instituições, da regulamentação que implementou o programa de avaliação de servidores, da duração do período avaliativo e pontuação mínima necessária para aprovação do desempenho, da metodologia de avaliação aplicada, dos critérios avaliados utilizados e das características do 


\section{AVALIAÇÃO DE DESEMPENHO DE TÉCNICO-ADMINISTRATIVOS EM EDUCAÇÃO NO ÂMBITO DAS INSTITUIÇÕES FEDERAL DE ENSINO SUPERIOR \\ DOI: http://dx.doi.org/10.5007/1983-4535.2014v7n3p182}

sistema de gestão de recursos humanos a partir dos modelos teóricos de Ulrish (1998) e no Modelo das Quatro Faces do RH de Tanure et al (2007).

Relativo a questão da regulamentação, fica evidente no que pese as regulamentações apresentadas na Lei 11.091/05 e no Decreto Lei 5.825/06, não existe um modelo padrão de regulação interna da avaliação de desempenho dentro das IFES. Cada instituição estabeleceu suas regulamentações próprias e nem todas cumprem o objetivo promover o desenvolvimento institucional, subsidiando a definição de diretrizes para políticas de gestão de pessoas e garantindo a melhoria da qualidade dos serviços prestados à comunidade, preconizado nas referidas legislações.

A análise das 18 IFES observa-se que 11 regulamentaram através de resoluções, uma única por programa, como no caso da UFBA. Também, a UFF regulamenta o processo de avaliação por portaria. Caso idêntico da UFRGS por decisão (regulação interna). As demais 4 IFES (UNB, UFSC, UNIFESP e UFRJ) não apresentam regulamentações internas formalmente instituídas, conforme Tabela 1.

Tabela 1 Instrumento de regulamentação

\begin{tabular}{|c|c|c|}
\hline Instrumento de Regulamentação & Quantidade & IFES \\
\hline Resolução & 11 & $\begin{array}{c}\text { UFJF, UFMG, UFSCar, UFV, UFC, UFES, } \\
\text { UFPA, UFPR, UFPE, UFRN e UFVJM }\end{array}$ \\
\hline Programa & 1 & UFBA \\
\hline Portaria & 1 & UFF \\
\hline Decisão & 1 & UFRGS \\
\hline Sem Regulamentação & 4 & UNB, UFSC, UNIFESP e UFRJ \\
\hline
\end{tabular}

Fonte: Elaborado pelos Autores

A não padronização dos períodos avaliativos é uma observação relevante na amostra da pesquisa. Importante salientar que das 18 IFES analisadas, na sua maioria (13 IFES) são utilizados os 12 meses definidos pela legislação (Decreto 7.133 de 19/03/2010, no seu artigo $2^{\circ}$ ). Nas demais instituições, as UFRJ e UFVJM utilizam 18 meses, a UFF com um período de avaliação de 9 meses, a UFBA apenas 6 meses e a Universidade Federal de São Paulo ainda encontra-se em fase de regulamentação.

A questão da despadronização também é aferida no que diz respeito aos requisitos mínimos para aprovação na avaliação, e sua consequência para os servidores sejam considerados aptos, variando percentuais de $60 \%$ a $70 \%$, e em casos de escalas simples de habilitado ou não habilitado. A Tabela 2 é ilustrativa. Recorda-se que é necessário superar o requisito mínimo para ser aprovado no programa de avaliação de desempenho, com o qual o servidor TAE fica habilitado a receber a progressão funcional por mérito, permitindo que o 
mesmo passe para o nível imediatamente superior da tabela de vencimentos do $\operatorname{PCCTAE}^{\mathrm{v}}$ a cada 18 meses, acrescendo seu vencimento salarial em 3,6\%.

Tabela 2 Requisito mínimo para habilitação na avaliação de desempenho

\begin{tabular}{|c|c|c|}
\hline $\begin{array}{c}\text { Requisito mínimo para } \\
\text { habilitação }\end{array}$ & Quantidade & IFES \\
\hline $70 \%$ & 5 & UFJF, UFSC, UFPE, UFV e UFPR \\
\hline $66 \%$ & 1 & UFRN \\
\hline $60 \%$ & 8 & UNB, UFSCar, UFES, UFPA, UFRJ, UFRGS, UFVJM e UFF \\
\hline Nota superior a 4 & 1 & UFC \\
\hline Habilitado/não habilitado & 1 & UFMG \\
\hline N/A & 2 & UFBA e UNIFESP \\
\hline
\end{tabular}

Fonte: Elaborado pelos Autores

Já no que diz respeito aos métodos avaliativos, encontra-se diversos procedimentos utilizados, como: escala gráfica, escolha forçada, avaliação por objetivos, avaliação por competências e avaliação por múltiplas fontes na modalidade $360^{\circ}$.

Observa-se então, que a utilização de formulários eletrônicos com adoção de escala gráfica, mais fáceis de serem aplicados e tabulados, fazem parte da maioria dos procedimentos avaliativos, perfazendo 14 universidades. Algumas se apropriam de ferramentas adicionais, 12 dessas IFES adotam a avaliação $360^{\circ}$, utilizando conjuntamente a avaliação por objetivos, agregando a pactuação de metas das equipes de trabalho e individuais atreladas ao planejamento da instituição e das unidades acadêmicas e administrativas.

As UFJF e UFMG utilizam esse mesmo ferramental, porém sem a escala gráfica pontuando os servidores desvinculado de objetivos, e sim através do acompanhamento com o andamento percentual das atividades das equipes de trabalho e dos servidores, método que tende a ser mais vantajoso que os formulários eletrônicos de escala gráfica. O caso das UFPE, UFC, UFRJ e UFVJM utilizam somente formulários tradicionais de auto-avaliação e avaliação da chefia e a UFSC utiliza o método da escolha forçada, essas sem nenhum comprometimento com as estratégias das organizações (Tabela 3).

Tabela 3 Métodos avaliativos utilizados pelas IFES

\begin{tabular}{|c|c|c|}
\hline Método utilizado & Quantidade & IFES \\
\hline $\begin{array}{c}\text { Múltiplas fontes 360\%/Avaliação por } \\
\text { Objetivos/Escala Gráfica }\end{array}$ & 3 & UNB, UFBA e UFPA \\
\hline $\begin{array}{c}\text { Múltiplas fontes } 360^{\circ} / \text { Avaliação por } \\
\text { Objetivos }\end{array}$ & 2 & UFJF e UFMG \\
\hline Múltiplas fontes 360\% Escala Gráfica & 7 & UFSCar, UFV, UFES, UFPR, UFRN, UFRGS e UFF \\
\hline Escala Gráfica & 4 & UFPE, UFC, UFRJ e UFVJM \\
\hline Escolha Forçada & 1 & UFSC \\
\hline N/A & 1 & UNIFESP \\
\hline
\end{tabular}

Fonte: Elaborado pelos Autores 


\section{AVALIAÇÃO DE DESEMPENHO DE TÉCNICO-ADMINISTRATIVOS EM EDUCAÇÃO NO ÂMBITO DAS INSTITUIÇÕES FEDERAL DE ENSINO SUPERIOR \\ DOI: http://dx.doi.org/10.5007/1983-4535.2014v7n3p182}

A correlação com os modelos de gestão foram efetuadas também com base na análise documental, apesar de não ter capacidade de envolver condições práticas adotadas pelas IFES fora das regulamentações internas, normalmente apresentam nos documentos funcionais e regulatórios, características que mostram uma predisposição da instituição em trabalhar a gestão institucional, que no nosso caso, se confirma ou não dependendo da forma como a avaliação é utilizada. Partindo, então, do pressuposto que toda avaliação por objetivos prescinde da realização de um planejamento, seja esse da unidade administrativa/acadêmica, seja institucional.

Nos modelos de Ulrish (1998) e das Quatro Faces do Recursos Humanos (2007), considera-se as avaliações por objetivos nas dimensões comuns de "parceiros estratégicos" dos dois autores. As que tem aspectos estratégicos associamos a metáfora do "construtor" do 4FRH. Como todas elas tem o setor de RH tradicional, buscam-se a todas as metáforas de "especialista administrativo", "defensor dos funcionários" e "executor" dos dois modelos. As dimensões de "agente da mudança" e "navegador" ocorreu alguma complexidade na interpretação, visto que são valores subjetivos e que apresentam relativa dificuldade de aferição. Apresenta-se no Gráfico 1 como a distribuição das IFES de acordo com as metáforas dos sistemas de gestão de Ulrish e Quatro Faces do Recursos Humanos:

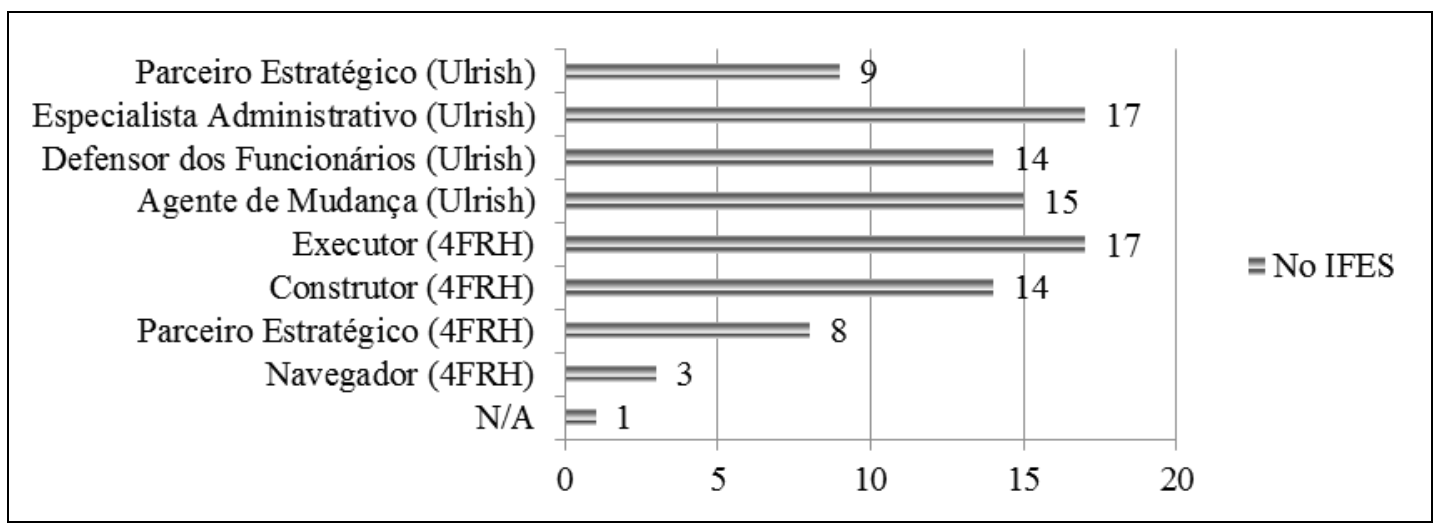

Gráfico 1 Apropriação dos modelos de gestão pelas ifes

Fonte: Elaborado pelos autores

Como resultado de nossa pesquisa, constatamos que nem todas as IFES se apropriam da ferramenta da avaliação de desempenho de maneira adequada, associando aos seus modelos de gestão e relacionando o instrumento ao planejamento das unidades acadêmicas e administrativas, e a instituição como um todo, perdendo a oportunidade de utilizar esse instrumento para melhorar seus processos internos e aperfeiçoar o desenvolvimento organizacional. 


\section{AVALIAÇÃO DE DESEMPENHO DE TÉCNICO-ADMINISTRATIVOS EM EDUCAÇÃO NO ÂMBITO DAS INSTITUICCÕES FEDERAL DE ENSINO SUPERIOR \\ DOI: http://dx.doi.org/10.5007/1983-4535.2014v7n3p182}

\section{CONCLUSÕES}

Após seis anos da publicação da legislação que regulamentou a avaliação de desempenho atrelada a carreira dos servidores TAE's da IFES, verificou-se nessa pesquisa e na prática vivenciada pelos autores, que existem várias lacunas e deficiências a serem preenchidas, exploradas e resolvidas no que tange a regulamentação, políticas institucionais, gestão de RH e dos servidores em suas equipes de trabalho, o que passaremos a abordar adiante.

As Leis 11.091/2005, 11.784/2008 e o Decreto 7.133/2010 regulamentam e estabelecem critérios e diretrizes para implementação e operacionalização das avaliações de desempenho, no entanto, não existe uma metodologia de avaliação padronizada definida, ficando a critério das IFES escolherem e implementarem a sua maneira. Nessa pesquisa constata-se a existência de universidades que ainda não conseguiram estabelecer seu modelo, e grande parte das que já instituíram não conseguem se apropriar adequadamente do ferramental necessário para tornar a avaliação de desempenho um instrumento de gestão. Passa-se então a delinear ações que, quando tomadas, podem auxiliar as instituições a terem sucesso nos seus modelos institucionais e de gestão de pessoas em seus diversos planos.

$\mathrm{Na}$ abordagem corporativa, as instituições necessitam efetuar seus planejamentos de curto, médio e longo prazo, visando se capacitar institucionalmente para alcançar seus objetivos. O Plano de Desenvolvimento Institucional é uma das ferramentas utilizada pelas IFES para tal fim, nele deverá estar contemplada a visão da Administração Superior têm para suas atividades de ensino, pesquisa e extensão. Estando intimamente articulado com a prática e os resultados da avaliação institucional, realizada tanto como procedimento auto-avaliativo, como externo.

No entanto nem sempre o PDI corresponde a realidade dessas organizações, muitas vezes ele é somente um instrumento para atendimento burocrático e suas informações nem sempre estão coerentes com o planejamento e as necessidades institucionais. Para que esse plano não seja uma "peça” ilustrativa e se incorpore às práticas da instituição, é preciso torná-lo um instrumento democrático e participativo, amplamente discutido e divulgado. Para isso, existe a necessidade de se fazer uma revisão anual de suas ações pelas Secretarias de Desenvolvimento Institucionais das IFES, fiscalizadas pelas Comissões Próprias de Avaliação, que devem ter seus funcionamentos induzidos e incentivados pelas instituições. 


\section{AVALIAÇÃO DE DESEMPENHO DE TÉCNICO-ADMINISTRATIVOS EM EDUCAÇÃO NO ÂMBITO DAS INSTITUICCÕES FEDERAL DE ENSINO SUPERIOR \\ DOI: http://dx.doi.org/10.5007/1983-4535.2014v7n3p182}

Ainda no âmbito da Administração Superior, esta deve ser permanentemente ativa no que diz respeito a difusão da cultura da avaliação institucional, fornecendo condições para o desenvolvimento dos instrumentos de gestão, oferecendo recursos humanos, financeiros e materiais para viabilizá-los.

As áreas de Gestão de Pessoas e Recursos Humanos devem possuir programas de capacitação e qualificação de servidores alinhados às necessidades preconizadas nas necessidades estratégicas da Instituição, no intuito de desenvolver as habilidades e competências necessárias para que os servidores possam contribuir para o atendimento das diretrizes de desenvolvimento institucional. Estes programas de capacitação, segundo a teoria da gestão das competências, devem estar alinhados aos programas de avaliação de desempenho, num ciclo contínuo de retroalimentação.

Devem, ainda, seguindo os ensinamentos de Ulrish (1998) e Tanure (2007), serem indutores na condução do alinhamento da gestão operacional a gestão estratégica da organização, passando pela gestão da mudança. Para isso, os profissionais de RH necessitam extrapolar suas funções burocráticas e atuarem como parceiros e consultores dos gestores das unidades acadêmicas e administrativas, no sentido de alinhar as metas dessas unidades aos objetivos institucionais preconizados no PDI. Esses novos profissionais de RH necessitam se profissionalizarem continuamente em suas atividades, desenvolvendo competências para criarem programas e regulamentações que perpassem as questões políticas e eleitorais das IFES.

No âmbito da infraestrutura há necessidade de se desenvolver, de forma otimizada, os sistemas de tecnologia da informação, efetivando o programa de avaliação de desempenho de forma integrada, fornecendo subsídios para os sistemas de capacitação, convergindo informações necessárias para que os gestores efetivem as políticas de gestão da competência dos servidores.

Os programas de avaliação de desempenho são efetivos e com melhores resultados quando os servidores são avaliados nas suas metas relacionadas a resultados e objetivos. Verificou-se também, que quando avaliados na modalidade $360^{\circ}$, tendem a ter um maior compromisso com os objetivos institucionais, visto que além de cumprir suas metas, igualmente são avaliados pelas chefias, colegas de trabalho e usuários de seus serviços.

As IFES, em sua totalidade, possuem em seus quadros servidores técnicoadministrativos qualificados para levar adiante as políticas institucionais. É necessário que 
estes servidores se sintam motivados a serem co-participes desse sistema de gestão, e isso é feito quando o servidor é integrado ao sistema decisório de sua instituição, passando a se sentir responsável pelos resultados obtidos.

\section{REFERÊNCIAS}

BALASSIANO, Moisés; SALLES, Denise Medeiros Ribeiro. Ambigüidades e implicações da Avaliação de Desempenho Funcional em uma Carreira Típica de Estado. EnANPAD 2004. Disponível em: 〈http://ead.enap.gov.br/moodle/mod/resource/view.php?id=3373> Acesso em: 22 de fevereiro de 2009.

BRANDÃO, H. P. Aprendizagem, contexto, competência e desempenho: um estudo multinível. 2009. Tese (Doutorado) - Universidade de Brasília, Brasília.

BRASIL. Constituição da República Federativa do Brasil, de 5 de outubro de 1988.

BRASIL, Decreto no 5.825, de 29 de junho de 2006. Estabelece as diretrizes para elaboração do Plano de Desenvolvimento dos Integrantes do Plano de Carreira dos Cargos TécnicoAdministrativos em Educação, instituído pela Lei no 11.091, de 12 de janeiro de 2005. Brasília.

BRASIL, Decreto n $\mathbf{n}^{\mathbf{7}} \mathbf{7 3 3}$, de 19 de março de 2010. Regulamenta os critérios e procedimentos gerais a serem observados para a realização das avaliações de desempenho individual e institucional e o pagamento das gratificações de desempenho. Brasília.

BRASIL, Decreto n. 84.669, de 29 de abril de 1980. Regulamenta o instituto da progressão funcional a que se referem a Lei ${ }^{\circ} 5.645$, de 10 de dezembro de 1970, e o Decreto-lei $\mathrm{n}^{\circ}$ 1.445 , de 13 de fevereiro de 1976, e dá outras providências. Brasília.

BRASIL, Lei no 8.112, de 11 de dezembro de 1990. Dispõe sobre o regime jurídico dos servidores públicos civis da União, das autarquias e das fundações públicas federais. Brasília.

BRASIL, Lei no 9.625, de 7 de Abril de 1998. Cria a Gratificação de Desempenho e Produtividade - GDP das atividades de finanças, controle, orçamento e planejamento, de Desempenho Diplomático - GDD, de Desempenho de Atividade de Chancelaria - GDC e de Desempenho de Atividade de Ciência e Tecnologia - GDCT, e dá outras providências. Brasília.

BRASIL, Lei no 10.861, de 14 de abril de 2004. Institui o Sistema Nacional de Avaliação da Educação Superior - SINAES e dá outras providências. Brasília.

BRASIL, Lei no 11.091, de 12 de janeiro de 2005. Dispõe sobre a estruturação do Plano de Carreira dos Cargos Técnico-Administrativos em Educação, no âmbito das Instituições Federais de Ensino vinculadas ao Ministério da Educação. Brasília.

BRASIL, Lei no 11.784, de 22 de setembro de 2008, Dispõe sobre a reestruturação do Plano Geral de Cargos do Poder Executivo - PGPE. Brasília. 
BRASIL, Medida Provisória no 431, editada em 14 de maio de 2008. Dispõe sobre a reestruturação do Plano Geral de Cargos do Poder Executivo - PGPE. Brasília.

BRASIL, Medida Provisória no 1.548, de 18 de dezembro de 1996. Cria a Gratificação de Desempenho e Produtividade - GDP das atividades de finanças, controle, orçamento e planejamento, e dá outras providências. Brasília.

BRESSER- PEREIRA, Luiz C. Da Administração Pública Burocrática à Gerencial. Revista do Serviço Público, 447(1) janeiro-abril, Brasília, 1996.

CAMPANTE, Rubens G. O Patrimonialismo em Faro e Weber e a Sociologia Brasileira. Revista de Ciências Sociais, Vol. 46, nº 1, pp. 153 a 193. Rio de Janeiro, 2003

CHIAVENATO, Idalberto. Desempenho humano nas empresas. São Paulo: Atlas, 1998.

EVANS, P.; PUCIK, V.; BARSOUX, J.-L. The Global Challenge: Frameworks for International Human Resource Management. Boston: McGraw-Hill, 2002.

Fleury, Afonso e Fleury Maria T. L. Estratégias empresariais e formação de competências, São Paulo, Editora Atlas, 2004.

GIL, Antônio Carlos. Gestão de Pessoas: enfoque nos papéis profissionais. São Paulo: Atlas, 2001

HANASHIRO, Darcy M.M., NASSIF, Vânia M.J., TEIXEIRA, Maria L.M. O papel dos profissionais de recursos humanos na universidade compartilhado pelos diferentes stakeholders: revelando as competências docentes. FACEF PESQUISA, V. 6, n.3, 2003.

Le Boterf, Guy. Desenvolvendo a competência dos profissionais, Porto Alegre, Artmed, 2003 ,

LUCENA, Maria Diva de Salete. Planejamento estratégico e gestão do desempenho de resultados. São Paulo: Atlas, 2004.

LUDKE, Menga \& ANDRÉ, Marli E.D.A. Pesquisa em educação: abordagens qualitativas. São Paulo, Editora Pedagógica e Universitária, 1986. 99p.

MARRELI, Anne F. Introducción al análisis y desarrollo de modelos de competências,(Online). Disponível em: http://www.oitcinterfor.org, 2008.

MATIAS-PEREIRA, José. Manual de Metodologia da Pesquisa Científica. São Paulo: Atlas, 2007

MESQUITA, Joaquim Cláudio Figueiredo. Avaliação de Desempenho para a Gestão por Competências, Santo Domingo, 2010. 
MOTTA-ROTH, Désirée e HENDGES, Graciela Rabuske. Produção Textual na Universidade. São Paulo: Parábola Editora, 2010

PAES DE PAULA, Ana Paula. Administração Pública Brasileira Entre o Gerencialismo e a Gestão Social. ERA, Vol 45, nº 1. Belo Horizonte, 2003.

PONTES, Benedito R. Avaliação de desempenho: uma abordagem sistêmica. São Paulo: LTr, 1987.

Santos, 1. A. dos; cardoso, R. L. dos S. Avaliação de desempenho da ação governamental no Brasil: problemas e perspectivas. In: concurso de ensayos del clad, 2001. Caracas.

Tanure, Betânia; Evans, Paul; Pucik, Vladimir. A Gestão de Pessoas no Brasil: Virtudes e Pecados Capitais. Rio de Janeiro: Elsevier, 2007. 210 P.

TANURE, Betânia; EVANS, Paul; CANÇADO, Vera L. As Quatro Faces de RH: Analisando a Performance da Gestão de Recursos Humanos em Empresas no Brasil. RAC, Curitiba, v. 14, n. 4, art. 2, pp. 594-614, Jul/Ago 2010.

TRUJILlo, N. R. Selección Efectiva de Personal Basada en Competencias. Revista do Serviço Público, Ano 51, N. 3, P. 99-119, Jul./Set. 2000.

ULRICH, david. Os Campeões de Recursos Humanos: inovando para obter melhores resultados, São Paulo, Futura, 1998.

Velasco, Simone; Silva, Marcela, Sistemática da Avaliação de Desempenho na Administração Pública Federal, 2010.

YIN, Robert K. The Case Study Crisis: Some Answers. Administrative Science Quartely, V.26, Cornell University, 1981.

YIN, Robert K. Estudo de Caso: Planejamento e Métodos. Porto Alegre: Bookman, 2001

Zarifian, Philippe. Objetivo Competência: por uma nova lógica, São Paulo, Atlas, 2008.

\footnotetext{
'Sistema Nacional de Avaliação do Ensino Superior, criado através da Lei no 10.861 de 14 de abril de 2004.

ii Programa de Apoio a Planos de Reestruturação e Expansão das Universidades Federais, instituído através do Decreto Presidencial no 6.096 de 24 de abril de 2007.

iii Stakehoders: termo utilizado na administração para representar as partes interessadas que estão de acordo com as práticas de governança coorporativa adotadas pelas organizações.

${ }^{\text {iv }}$ A abordagem divergente: reconhece que o contexto é absolutamente importante para identificar a melhor forma de gestão. (TANURE et al, 2007).

` Instituído pela Lei 11.091/05, o Plano de Cargos e Carreira dos Servidores Técnico-Administrativos em Educação determina as classes e padrões de vencimentos conforme Tabela 3.
} 